\title{
Using practical wisdom to facilitate ethical decision-making: a major empirical study of phronesis in the decision narratives of doctors
}

\author{
Mervyn Conroy ${ }^{1}$, Aisha Y. Malik ${ }^{2,4^{*}}$, Catherine Hale ${ }^{2}$, Catherine Weir ${ }^{1}$, Alan Brockie ${ }^{1}$ and Chris Turner ${ }^{3}$
}

\begin{abstract}
Background: Medical ethics has recently seen a drive away from multiple prescriptive approaches, where physicians are inundated with guidelines and principles, towards alternative, less deontological perspectives. This represents a clear call for theory building that does not produce more guidelines. Phronesis (practical wisdom) offers an alternative approach for ethical decision-making based on an application of accumulated wisdom gained through previous practice dilemmas and decisions experienced by practitioners. Phronesis, as an 'executive virtue', offers a way to navigate the practice virtues for any given case to reach a final decision on the way forward. However, very limited empirical data exist to support the theory of phronesis-based medical decision-making, and what does exist tends to focus on individual practitioners rather than practice-based communities of physicians.

Methods: The primary research question was: What does it mean to medical practitioners to make ethically wise decisions for patients and their communities? A three-year ethnographic study explored the practical wisdom of doctors $(n=131)$ and used their narratives to develop theoretical understanding of the concepts of ethical decisionmaking. Data collection included narrative interviews and observations with hospital doctors and General Practitioners at all stages in career progression. The analysis draws on neo-Aristotelian, Maclntyrean concepts of practice- based virtue ethics and was supported by an arts-based film production process.
\end{abstract}

Results: We found that individually doctors conveyed many different practice virtues and those were consolidated into fifteen virtue continua that convey the participants"collective practical wisdom', including the phronesis virtue. This study advances the existing theory and practice on phronesis as a decision-making approach due to the availability of these continua.

Conclusion: Given the arguments that doctors feel professionally and personally vulnerable in the context of ethical decision-making, the continua in the form of a video series and app based moral debating resource can support before, during and after decision-making reflection. The potential implications are that these theoretical findings can be used by educators and practitioners as a non-prescriptive alternative to improve ethical decision-making, thereby addressing the call in the literature, and benefit patients and their communities, as well.

Keywords: Phronesis, Practical wisdom, Practice virtue ethics, Decision-making, Clinical leadership, Neo-Aristotelean

*Correspondence: ath3@hotmail.com; aisha.malik@conted.ox.ac.uk ${ }^{4}$ Department for Continuing Education, University of Oxford, Oxford, UK Full list of author information is available at the end of the article

\begin{abstract}
Background
The health and well-being of people is dependent on medical and public health decision-making. In recent years, there have been calls for using phronesis (practical wisdom) for medical-related ethical decision-making as a complement to evidence-based practice [1]. This is
\end{abstract}

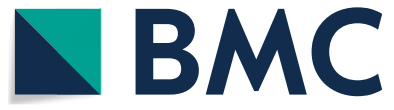

(c) The Author(s) 2021. Open Access This article is licensed under a Creative Commons Attribution 4.0 International License, which permits use, sharing, adaptation, distribution and reproduction in any medium or format, as long as you give appropriate credit to the original author(s) and the source, provide a link to the Creative Commons licence, and indicate if changes were made. The images or other third party material in this article are included in the article's Creative Commons licence, unless indicated otherwise in a credit line to the material. If material is not included in the article's Creative Commons licence and your intended use is not permitted by statutory regulation or exceeds the permitted use, you will need to obtain permission directly from the copyright holder. To view a copy of this licence, visit http://creativecommons.org/licenses/by/4.0/. The Creative Commons Public Domain Dedication waiver (http://creativeco mmons.org/publicdomain/zero/1.0/) applies to the data made available in this article, unless otherwise stated in a credit line to the data. 
because the latter does not consider the particularities of any given case and context.

Although Gallagher et al. [2] argue that doctors are motivated primarily by deontological (guideline or rulebased) approaches to decision-making in the context of medical practice, the quantity of such guidelines means that this prescriptive approach has become unmanageable. One estimate suggests that there may be more than 7000 deontological guidelines for clinicians to follow, with many being added every year [3]. Practitioners note that the growing use of ever-closer codification of medical practice is not able to take into account the complexity of caring for patients with multiple comorbidities and within difficult contexts [4]. The abstractness of principle-based approaches raises concerns about their utility in decision making in complex clinical context $[5,6]$. Further, Torjuul et al. [7] suggest that meeting the expectations of patients, colleagues and society makes doctors professionally and personally vulnerable. For instance, although doctors' main concern are their patients, in an environment of resource and regulatory constraints, meeting patients' expectations and distributing health care is challenging [7]. We argue that the theory presented in this paper offers a partial 'antidote' that makes the process of ethical decision-making easier, potentially reducing feelings of vulnerability and can build physician resilience.

Our research responds to the call for overcoming the limitations of the dominant deontology-based approach and meets the need for a new approach with a conceptual framework used as a moral debating resource for cultivating phronesis (practical wisdom) in the process of making ethical decisions.

Phronesis is a conceptual approach to ethical decisionmaking grounded in an accumulated wisdom gained through previous practice dilemmas and decisions. In effect, phronesis is an "executive virtue" that keeps stakeholders central to the decision-making process, allowing ethical choices to be executed in practice [8]. In their account of ethical decision-making, Jonsen et al. [9] report that the fundamental difficulty in all clinical settings is uncertainty, noting that the biological side of the uncertainty problem is severe because it is often very hard to be sure of a diagnosis or be certain that a specific treatment will work. Additional layers of uncertainty further compound this situation. For instance: What do patients prefer? Do they value length or quality of life? Do they prefer treatment (or no treatment) in line with religious or moral beliefs? Moreover, understanding the views of interested parties is essential: Does the patient's family have wishes? Does the hospital or health system have certain priorities of what can and cannot be treated due to financial constraints? Regardless of such preferences, what is the right or wrong thing to do? What if patients, relatives and hospitals prefer courses of treatment (such as antibiotics) that are not in the collective interest of the community to give?

When different moral and social problems begin to interact with each another, medical decision-makers may not be certain about what is best for patients and society, and how best to achieve optimal outcomes for both, simultaneously. Decision-makers must choose that what is in the best interest of patients and society is also in line with good clinical practice and has a good chance of working in practice.

Toulmin [10] and MacIntyre [11] align with each other in arguing for a recovery of the virtue of practical judgement to overcome disagreements and conflicts in the form of Aristotle's phronesis [12]. In Aristotle's work, phronesis is the intellectual virtue that helps turn one's moral instincts into practical moral action [13] by providing the practical know-how needed to turn virtue into successful action and enables phronimos to weigh up the importance of different virtues and competing goals in a given moral situation [14]. While moral virtues enable us to achieve the end, phronesis, makes us adopt the right means to that end [13:161]. Both moral virtues and phronesis work in tandem. In the absence of the former, phronesis degenerates into a "certain cunning capacity for linking means to any end rather than to those ends that are genuine goods for man" [11]:154]. Whereas, in the absence of phronesis, we may be lost in the moral maze.

Building on Jonsen and Toulmin [15] a number of authors [16-20] have developed theoretical accounts of judgement in medicine based on Aristotle's account of phronesis being the kind of practical wisdom that is needed to promote the good in morally difficult situations.

Pellegrino and Thomasma [16] provide the most forceful defence of the virtue-theoretic approach to medical ethics. They write that rule, or principle-based approaches to medical ethics are "too abstract" and "too formularized and far removed from the concrete human particulars of moral choice" [16]:19]. Alternatively, phronesis being medicine's "indispensable virtue" plays a crucial role in providing an essential connection between seeing or understanding what is right or good and knowing how to do good [16]:84].

Because different virtues can pull doctors in different directions (e.g. compassion drives her to give an optimistic assessment to a patient and honesty drives her to tell the truth), phronesis helps put virtues in the "proper order of priority and to make the right and good decision in the most difficult situation" [21]:382]. In the "people professions' the culture of mere compliance to rules and guidelines $[14,22]$ tends to oversimplify the complex 
clinical situation, making patients single-pathology entities rather than the multifaceted (medically and socially) humans they are, who require a holistic approach. Focussing on the patient as a person is imperative; science alone is not enough to understand the complexity of the case $[21,23,24]$. A recurrent theme of practice virtues being argued for as important is made in Carr et al. [25] and Kristjansson [14], and further supported by Jonsen and Toulmin [15], Pellegrino and Thomasma [16], Pellegrino[21], Montgomery [18], Toon[19] and Kaldjian [17].

Although there has been a drive to theorise about the importance of empirically-informed ethics [26-28], attempts to study clinical-judgement as phronesis using empirical data are rare. Notable exceptions are Jordens and Little [29], Little et al. [30], Jones et al. [31] and Conroy et al. [32]. However, all of these studies have been limited by small sample sizes. A clear gap existed for a large empirical study to inform the development of a virtue-based phronetic approach to medical and public health decision making.

We use phronesis as a theoretical frame to analyse the narratives and the observations on medical decisions that our participants conveyed both as wise and not so wise for patients and their community. Being within the neoAristotelean practice virtue ethics theoretical framework ([11], the concept of phronesis includes the telos of wellbeing for all in society.

We acknowledge other alternatives to deontological reasoning such as casuistry, narrative ethics and discourse ethics [e.g. 33]. The choice to focus on a practice virtue ethics approach came from a combination of the gap and emphasis in the literature, as outlined above, and directly from feedback from policy makers, academics and practitioners at the first workshop for this study [8]

The first step in practice virtue ethics is to understand the virtues that are considered by communities of practitioners, in this case the medical practice, to be important for their practice. Real cases communicated through stories or narratives, according to Montgomery [18], offer the best approach to eliciting practice virtues. The ontology of narrative conveying and transmitting practice virtues is supported by MacIntyre [11]. Therefore, to fill the gap in understanding, outlined above, we started our research with the following questions:

1. What does it mean to the medical community to make ethically wise decisions?

2. What virtues do the medical community convey as important for decision-making?

3. What approach do medical practitioners use to navigate the virtues they consider important when making decisions?
These questions formed the basis of a three-year study (2015-2018), 'Phronesis and the Medical Community' (PMC), which used a narrative and arts-based methodology to understand what it means to a community of UK medical practitioners to make ethically wise decisions for patients and their communities. Narratives from all medical career stages were collected. Following Kaldjian [17] and MacIntyre [11], we critically examined the practice narratives with particular attention to the virtues conveyed.

This paper describes the methodology, summarises our findings, discusses their contribution to ethically wise decision-making and suggests implications for medical education, policy and research.

\section{Methods}

Our research methods are based upon three main sources. From the humanities, we draw on the practice virtues philosophy of MacIntyre [11] and his argument that practitioner narratives convey the virtues of the practice of interest: narratives "humanize" situations and convey "what matters to us" [34, 35]. From social sciences, we use Flyvbjerg et al.s [36] phronesis-based ethnography to contextualize the collected stories. From the arts, we draw on a participatory video production approach [37], where the research team and some of the participants are involved in iteratively producing a film series and app that convey the collective set of virtues derived from the narratives [38].

Our data sources were in-depth, semi-structured interviews and direct observation of medical decisionmaking at multi-disciplinary team meetings (MDT). This approach allowed us to collect narratives and consider contexts, which indicated what participants considered to be ethically wise decisions and those which they considered to be unwise for their patients and communities. Our methods and data sources are appropriate to answering our three research questions and build on those used in other studies with an interest of understanding practice virtues [e.g. 39]. We draw on the language used by the participants when they refer to their practice and then changed that to a practice virtue. For example, practitioners may refer to 'negotiates' and that is interpreted as an action referring to practitioners negotiating with patients and the equivalent practice virtue would be 'negotiation'.

\section{Data collection}

Three communities of doctors were interviewed from mid-2015 to early 2017. Interviews took place during three time periods: 
1. Beginning of formal medical study (2nd year) and end of formal medical study (5th/final year)

2. On placement at the end of formal study, Foundation year 1(FY1) and Foundation Year 2 (FY2) and then in GP or Consultant traineeship.

3. Established GPs and medical consultants with 5 years or more experience.

131 doctors were interviewed. Table 1 shows the number of participants per cohort.

Ethics approval was obtained from the Science, Technology, Engineering and Mathematics Ethical Review Committee, University of Birmingham (reference ERN_15-0172) and the Health Research Authority REC (reference: 18/HRA/0203) for observations.

Eligible doctors and medical students were identified with the help of the academic and administration coordinators at the three participating medical schools (of University of Birmingham, University of Warwick and University of Nottingham) and their local NHS Trust hospitals. Thereafter, using a snowball sampling technique, more doctors were approached and invited to participate via emails. All communication between interested potential participants and researchers was treated as confidential. Emails did not reveal who else was contacted. All medical students, FY1, FY2 doctors and experienced doctors who were interviewed were asked if they would consent to observations. Observations were carried out from August 2017 to November 2017.

Of the $48 \mathrm{FY}$ ( 1 and 2$)$ cohort 13 were interviewed twice, first when they were in FY 1 and re-interviewed when they moved to FY2, to understand to what extent their phronesis develops as they move from FY1 to FY2. Non-participatory observations were conducted when four experienced practitioners, were working with multidisciplinary teams or peer groups to make decisions for their patients.

Participants were sent participant information sheets. Those who consented were invited for an interview. Semi-structured interviews (SSI) were conducted that developed from story gathering methods [39]. The interviewer started by explaining that we were interested in exploring: (i) the participant's experience of involvement in making ethical/wise decisions; (ii) whether their own

\section{Table 1 Number of participants per cohort}

\begin{tabular}{lr}
\hline 2nd year & 27 \\
5th year & 25 \\
FY 1 & 28 \\
FY 2 & 20 \\
Experienced & 31 \\
Total & 131 \\
\hline
\end{tabular}

or those of others they work with; (iii) whether they perceived them to be good/wise or not so good/unwise decisions. Although an aide memoire was prepared, to be used as prompts only, participants started their accounts wherever and however they wanted. If they did not respond to this open start, the interviewer might prompt with 'It seems difficult for you to start on this subject, would you like to start by talking about the difficulty?' They were then asked about the instances or stories that they subsequently alluded to and so, the interview built on participants' responses. [8]

Most interviews were conducted face to face at the medical schools for the medical students, for the practicing doctors they were conducted at the hospitals where they worked, after they had completed their clinical duties, while a few interviews were conducted via telephone. The interviews, which lasted between 40 and $60 \mathrm{~min}$, were audio-recorded and transcribed verbatim. Four FY participants and two experienced doctors from across the three sites provided a diary focusing on experiences of meaningfulness and puzzlement that they indicated represented practical wisdom (wise or unwise decisions). The narratives were used to generate discussion and along with the observations provided the basis for storyboards and scripts that led to the production of a video series. Prior to video production the scripts were fed back to some of the doctors (two consultants, two GPs and a FY doctor) who attended a steering group meeting to ensure they were a fair and balanced representation of the kind of stories that circulate in their practice environment. Subsequently the alpha version of the videos produced were reviewed by nineteen medical practitioners (Consultants and GPs) medical ethics' tutors and CPD providers at a workshop, held in March 2018. The feedback from workshop participants was collated and sent to the film production team for an update to a beta version of video series [38].

\section{Data analysis}

Interview data were analysed thematically by reading and rereading the transcripts to make the transition from literal meaning to practice virtue themes. Data were organized and coded using NVivo 11 Plus. Coding and analysis were conducted simultaneously. The research team met regularly, initially to discuss coding strategies and categories and then to check (inter-coder reliability) and to consolidate virtue themes.

The nature of the practice virtues including phronesis was examined through two theoretical lenses: MacIntyre's [11] practice based virtue ethics and Kaldjian's [40] medical phronesis. Findings from the latter are presented elsewhere [41]. 
Table 2 Virtue Continua

\begin{tabular}{|c|c|c|c|}
\hline Virtue (V.) & POLE1(excess) & MEAN & POLE2 (deficiency) \\
\hline 1 & Doctor decides & Negotiation & Patient decides \\
\hline 2 & ALL get treatment & Justice/Fairness & Select few get treated \\
\hline 3 & Overly trusted & $\begin{array}{l}\text { Trustworthiness/(including maintaining } \\
\text { confidentiality) }\end{array}$ & No trust \\
\hline 4 & Constant litigation worry & Lawfulness & Ignore legal constraints \\
\hline 5 & $\begin{array}{l}\text { Constantly seeks Guidance from peers and/ } \\
\text { or professional bodies }\end{array}$ & $\begin{array}{l}\text { Collaboration (Making Collaborative Deci- } \\
\text { sions/Seek guidance) }\end{array}$ & Self-guided/Does not consult \\
\hline 6 & Use own values and beliefs & Cultural competence & Go with patient's values and beliefs only \\
\hline 7 & Too involved (Over emotional) & $\begin{array}{l}\text { Emotional Intelligence (including Interper- } \\
\text { sonal Communication) }\end{array}$ & Distant/Aloof \\
\hline 8 & Treat at all cost & Awareness of limits to treatments & Limited consideration of treatment options \\
\hline 9 & Constant mentoring/overly directive & $\begin{array}{l}\text { Mentorship (and being an approachable } \\
\text { mentor) }\end{array}$ & No interest in mentorship \\
\hline 10 & $\begin{array}{l}\text { Trying to cater to all aspects - Arts/humani- } \\
\text { ties science, spiritual and physical }\end{array}$ & Balanced approach & Just one approach-e.g. science/clinical only \\
\hline 11 & Over-analytical (Navel gazing) & Reflexive & Never reflect \\
\hline 12 & Foolhardy risk taker & Courage (to speak out and act) & Cowardice (Avoids conflict) \\
\hline 13 & Thinking they are bullet proof & Resilience & Avoidance of any stress \\
\hline 14 & Obsessed with finances/resources & Resource awareness & No consideration of resources \\
\hline 15 & Seen it all/know it all/can deal with anything & Phronesis & $\begin{array}{l}\text { Applies purely theory or just follows guide- } \\
\text { lines }\end{array}$ \\
\hline
\end{tabular}

After four iterations, a set of 15 virtues were agreed. These 15 virtues were put into virtue continua (Table 2). This consolidated set of virtues, along with the narratives and observations, were used as the basis of the video series.

Use of combined narrative and film production methodology enabled MacIntyre's [11] practice virtue ethics to emerge from our data as the 'collective practical wisdom': a non-prescriptive moral debating resource, that reflects what it means to participants to make ethical decisions that contribute to the good for patients and their communities. The close fit between our data and practice virtue ethics concepts in video and app format, including phronesis, means they offer a new and accessible resource for doctors at all stages in their professional careers. Practitioners may find the resource aids ethical reflection about their decision-making, as a guide to ethical action, and as a foundation for resolving discrepancies between virtues.

\section{Results}

Participants conveyed many different practice virtues but no one participant conveyed all 15 virtues. The more experienced participants conveyed more of the virtues than the less experienced participants. This finding connects to the neo-Aristotelian framework of practice virtues constructed by MacIntyre [11] and advocated by Carr [42]. MacIntyre suggests determining the practice virtues across a peer group of practitioners rather than individual moral characters. This fits with the notion of diversity in practitioner contributions bringing a more robust set of virtues to the practice $[25,42]$. The consolidated 15 virtues we present here represent a "starter-set" of virtues for medical practice that are open for debate and challenge from others. As a non-prescriptive debating resource, this combined phronesis offers a powerful way for those in medical education and practice to debate forms of decision-making to serve the best interest of patients and their communities. The arts-based element of the analysis was used to produce a seven-part video series, which is an enacted form of our participants' 'collective practical wisdom. The videos offer a highly accessible form of moral debating resource for reflection before, during and after medical decision-making (for an example see episode 3 at: https://www.youtube.com/ watch?v=Azkxeddnlpg).

\section{Virtue continua}

We present our findings as a "virtue continua" (Table 2) before presenting them in text form. The virtue continua show the virtues conveyed by our interviewees in their narratives. Each virtue extends from pole-to-pole via a mean.

Here we present four examples from Table 2, above, to demonstrate how the data supported the analysis. Additional file 1 shows all the 15 virtues gleaned from the 
participants' narratives and Additional file 2 the virtues from observation data.

\section{Negotiation (V.1)}

Many participants produced narratives about negotiating with patients and others when making decisions about treatment. Some conveyed the doctor's role as providing suitable and relevant information to enable patients/ carers to come to a decision. However, other narratives reflected that providing expert advice and guidance in the light of clinical facts was important to patients while also taking patients' views into account. This enabled informed choice in partnership with the patient:

I guess that would be my approach, just to seek out as many facts as I possibly could on the one hand, and for more... difficult decisions, just talking to the patient and trying to get to know them a bit better and their kind of particular outlook ..... and then possibly based on that, kind of guide them to a decision that I think might suit them better. (B102).

Experienced doctors spoke about the importance of dialogue and how exchanging information resolves conflicts and enables patients to make an informed choice:

[A] a constructive conversation both ways. I've got something to say but let's not jump to a decision now, because that would be wrong. (BX02).

However, decisiveness was respected both by doctorsin-training and by some patients they encountered. It was reported that some patients implicitly sought paternalistic guidance, as they may find decision-making burdensome, relying on the doctor's expertise and knowledge to guide them:

Sometimes people do respond well actually to someone taking control of the situation, even if it's in a way that you would think would surely be completely inappropriate, but [the patients] respond well to it. (B112).

A FY doctor reflected (in their diary) on the distress caused knowing fully well that if a surgical procedure is not conducted it would prove fatal for the patient but agreed to the request of the patient:

If felt very sorry for the patient, and a little disturbed at the idea that this was almost certainly going to kill her..... I therefore found it difficult to reconcile my wish to respect her autonomy and her decision making, and the horrific consequences of her choice. (W 108).

Sometimes, some participants said that persuading patients in their best interest is necessary because:
[A] patient doesn't understand the severity of the decision they're making, and perhaps only when they've seen people who don't have the procedure done or don't have an operation might they learn... the actual nature of the decision they're making, because we see it, whereas they don't. (WX02).

Sometimes doctors, led by patient autonomy, assume the role of information providers, enabling patients' decisions to be implemented:

But, for me, a good decision is one where the patient is the one who essentially makes the decision, or puts forward their wishes, and we then, as the clinicians, allow that decision to come to fruition. (B107).

Collaboration (Being Collaborative/seeking guidance) (V.5) Many participants narrated stories about the presentday clinical paradigm being where professionally isolated decision-making is often neither advisable nor possible. Seeking to involve all those entrusted with a particular patient's care allowed holistic, tailored decisions. Counsel from multiple parties and professional guidelines was reported to be valuable. This was corroborated by our observations of different MDT meetings. When making decisions for complex cases, team members frequently found that the progressive decisions reached and displayed on the whiteboards were useful, as "they help prioritise and review decisions." (Obs.1).

Guidelines, though useful, require contextual awareness that can be provided by those who know the patient well, such as:

[T]he nursing staff who cared for the patient throughout, I relied on hugely ... and even the night sister ... just made it more logical, and decisionmaking more logical. I do rely on my consultants for the ultimate decision quite a lot of the time. (BX01).

In observation 2 , the roles of the occupational therapist $(\mathrm{OT})$, physiotherapist (PT) and speech therapist were seen to be central to certain patients' treatment because they had the most up-to-date information. The Registrars and Consultant relied on the OT and PT to provide almost the whole information summary. These collaborative discussions become critically important when making "deprivation of liberty" decisions. This observation made it clear that:

The lead consultant would ask questions and appeared to be kind of taking it all in, cross-referencing information he got with his records on his computer. More often than not, he would defer to the decisions of the PT and OT.....The nurse had a lot 
of say as well about how patients were progressing towards their goals. (Obs. 2).

This approach was not universal, though. At another MDT observation (Obs. 3), the discussions were mostly contained amongst the doctors, with barely any input from other staff.

Most medical students were of the view that it is far better for "not-so-experienced doctors" to defer to people with more experience:

[Y]ou know, bigger decisions, you're not going to want to take that onto yourself, you're going to defer to people that have got the experience. (W203)

Several newly trained doctors conveyed that they appreciated the opportunities to seek guidance from, and feel reassured by, more experienced doctors. This was observed (Obs. 3) in an Emergency Department environment, when the junior doctor requested the Consultant to discuss "an older patient with complex health and social problems", because:

.... they've probably made that [decision] before and they can tell you with experience the outcome and why. And they might come up with ideas as to why your idea might not be the best for that patient. (W101).

Experienced doctors also conveyed that they seek guidance in challenging cases as it helps them clarify the situation and make better decisions:

...sometimes that consensus is really useful because you're basically going through the arguments ... and again clarifying some of the aspects of it, I think. (BX11)

Some participants referred to guidelines being interpreted contextually. This could result in referring to more experienced doctors to gain insights into wider interpretations of the guidelines:

...so we've got an SHO ....[with] very good book knowledge, he's very academic, [and] knows the guidelines for everything off by heart but he doesn't really have a grasp of the fact that not every patient can be treated as per guidelines. And we've been trying to explain to him that a guideline is just that, it's a guideline, it's not rigid; it's meant to guide your practice.... he's had real issues with not calling for senior support because he feels that he's got a guideline to follow and that he follows it.. (WX05).

\section{Cultural competence (V.6)}

Some stories conveyed that respecting patients' values and beliefs is important. Many of the participants said that they consult their colleagues to understand cultural issues. However, some participants narrated experiences where the doctor chose to follow their own beliefs and values, rather than the patients'. One doctor experienced a situation where a doctor refused an intervention that challenged their personal beliefs leading to treatment delay. They said:

[I]t is important to park your own values. You should not allow those values to affect the decision. (BX04).

Similarly, reflecting in their diary a FY doctor wrote:

However, one point I am completely certain of is the importance of professionalism. I feel one should never impose their views on to a patient (W103).

A 5th Year medical student told of a consultation in a sexual health clinic, where the doctor seemed judgemental towards a patient:

[H]e said something like, 'Are you gay or straight?' or something. Just, like, which is incorrectly phrased? There's far more, like, tactful ways to do it. But he, kind of, shouted at them, so, 'Are you gay?' kind of thing. (B501).

Cross-cultural sensitivity was stated to be important in building trust. Rehabilitation, for example, is conveyed as following a "white Anglo-Saxon" model. An experienced doctor explained:

I think there's - generally there's mistrust of the NHS that we pull out too soon, and we don't do everything that's possible,. don't do everything we should be doing.. but that's compounded by a cultural view of life I think..... there is[at times] a cultural clash, so there is mistrust that can be on both sides. The only way to get around that is to recognise that there is a difference in view and maintain open dialogue. (BX05).

\section{Emotional Intelligence (including Interpersonal communication) (V.7)}

Good interpersonal communication was conveyed as commendable by our participants, because:

[Y]ou can be the greatest doctor in the world but if you can't communicate, nobody will do what you say, will they? (BX103). 
However, some conveyed that having the clinical knowledge regarding the disease is also essential:

[Y]ou can be a very compassionate person, but a useless doctor if you don't know what you're doing. (W207),

Some participants narrated experiences where an apparent lack of interpersonal communication skills was displayed by a doctor:

...the clinician who saw her [the patient] wasn't very communicative and reassuring in his approach to the patient... [the patient] was having a miscarriage, [the clinician] left it at that; left the room, and I was standing there with a very distraught couple... I told the clinician and he said, 'Oh they'll probably figure it out some way along the line.' And wasn't very keen on going back and telling the patient - reassuring them. (W502).

Others conveyed how empathic communication made patients amenable to discussion:

I think you have to, I suppose, temper your objective, rational facts for your decision-making process in a way that comes across as empathetic and sympathetic and looking at a bigger picture beyond the current situation; and also to help parents to think about things from their baby's view. (BX12).

\section{Phronesis (V.15)}

The development of practical wisdom was conveyed by most interviewees as sequentially experiential. One medical student termed it "learned experience" (N203), while a FY doctor spoke of it as a "mix of nurture and nature" (B104, Follow-up). For one experienced doctor:

...some people are inherently wiser, they are really wise people...now, whether that wisdom is inherent or ... is simply because that person has walked past that journey ahead of me. (NX05).

Experience can, however, lead to an assumption about personal knowledge. Another FY doctor recounted how the Consultant seemed to show a lack of compassion and so:

"... experience makes you better at making clinical decisions... but not necessarily in terms of ethical decisions... a lot of people get stuck in their ways. (B504)

Assuming that they "know it all" and following a textbook approach can, according to another participant, cause a doctor to be caught out:
You can't make a decision based on what the textbooks say... because if the textbooks say it, you can only say that that's right $99 \%$ of the time. There will always be the one case that will catch you out if you treat everybody the same... there's things that are really rare, but they still happen. (WXO2).

An experienced doctor reported another risk that arises with experience and seniority as being "arrogant or foolhardy." (BX04). Similarly, another experienced doctor reported on a senior consultant who regularly over-ruled based on experience rather than book knowledge:

Because evidence-based medicine tells you something else, but the experience of this doctor was something different, so there is, kind of, a clash between the two, rather than both going forward in a symbiotic relationship... Which is why I'm wary of saying that wisdom is the most important thing. (NX04).

Phronesis was variously described as the collation of holistic information, both clinical and social, from different sources, as well as being able to weigh that up against protocols, guidelines, various situations encountered in the past and then getting other "opinions, other approval, putting the situation to a new pair of eyes, and saying okay this is what I have got here." (B106).

But for some medical students, phronesis seemed to be narrowly defined as diagnostic skills (i.e. techne) as opposed to the broader process of a holistic decisionmaking (as described by FY and experienced doctors):

You know you learn by example, by following what someone else is doing... the art and the science of medicine... you need the clinical knowledge and then you need the experience to know how to apply it and when to apply it. (W207).

Another medical student spoke of consultants with a "repertoire of patterns" (W209). However, experience and "time served" were not enough to guarantee wise decision-making, and certain other virtues were seen as key to phronetic decisions. For instance, being reflective, "open to insight" (WX04) and being consultative: " always questioning what the right thing to do is." (B110). There were those who considered it as intuition, "a sixth sense" (NX02).

Phronetic decisions were often seen as the avoidance of the rigid application of rules and guidelines, what was termed by one experienced doctor as the "protocolisation of medicine" (WX03). In medicine "it is this difficulty of managing an illness rather than treatment of an illness which is the more difficult bit and there are never going to be mathematically accurate answers." (WX06). 
Phronetic decisions were often conveyed as practical and experiential:

... where wisdom comes from, it's a lot of thinking back to your past experiences and what you did badly, what you did well and trying to apply that... You've just got to think about in an ideal world what you want to do, and then think how you could possibly get as close to that with what you've got. (B110 $F P)$.

\section{Discussion}

The virtue continua in Table 2 show fifteen virtues, including phronesis, and the spectrum of actions for each, from deficiency to excess via a mean. This table represents the consolidated 'collective practical wisdom' conveyed in the decision narratives of the study participants. These fifteen virtues were conveyed in small sets or individually in the narratives collected from medical practitioners. Thus, they combine diversity of thinking and experience across the medical community interviewed and observed. These practice virtues represent a collective of what is required to come to wise decisions that are best for patients and their communities.

However, we are not claiming that they represent a final list of virtues that all practitioners should be following. Instead, they are formulated as a response to MacIntyre's [43] identification of a vital but missing component in professional education (including medics and other health professionals) of moral debating resources. The shared 15 virtue continua provide and act as exactly that, a stimulus for reflection and moral debate. We therefore argue that it is now possible to cultivate phronesis through that reflection and debate, to support the process of arriving at decisions that are right for the range of cases and contexts that practitioners are faced with.

These findings provide empirical evidence to support the theory that good practice emerges from agreeing the virtues across a group of people who conduct that practice $[20,44,45]$. Pellegrino and Thomasma write about the virtues of compassion, prudence, justice, trust, fortitude, temperance, integrity, respect and benevolence [16]. In her encounters with empathetic doctors, Kristiansen, narrates how the humanity of doctors helped make sense of the suffering and loss she experienced, long after the clinical encounter had ended [46]. The flexibility of this new virtue continua allows practitioners with a preference for these virtues to be included or merged with one of the fifteen presented in Table 2 . Interestingly this was reported by some of the research participants as part of 'collaboration' virtue (V.5 in Table 2), in that collaboration needs to exist not just with other practitioners but with any other guidance from professional bodies or other sources such as academic literature on the topic. This may lead to apparent disjunctions between virtues put forward in the fifteen here and those from other sources. However, since these new continua are not prescriptive, i.e. 'this is how it should be done', but instead a stimulus for moral debate, this would mean that the resource is fulfilling the role of providing a moral debating resource. It is then up to the community of practitioners to decide what virtues and continua are of relevance to the case, or cases, at hand. Thus, this is not a case of empirical trumps theoretical, or any other guideline for that matter, but simply a way of cultivating practical wisdom within and across practices through the moral debate that ensues. The flexibility in the continua allows for the two to be integrated, which is the role they are designed to fulfil to ensure that the diversity in the community is fully synthesised.

This also applies to community-based moral reasoning which may on occasion generate tension with individual reasoning. Participants consider that ethically wise decisions are guided by their medical knowledge (techne) and virtues, including the ability to understand patients' values [47]. Participants conveyed that negotiating treatment plans was important; although some reported relational interdependence, grounded in relational ethics, played an important role in making practically wise decisions $[24,48]$. Participants also suggested it is helpful to collaborate with those who know the context and can advise whether the decisions made are applicable in the real-world [1]. They indicated that seeking guidance on making decisions, especially in complex situations, from colleagues either senior or peers who have experiential knowledge, provides reassurance. This notion is corroborated by the nursing profession $[49,50]$. Resource constraints (time and finances) were reported as affecting communication and decisions made, and "provide the conditions in which unsafe acts occur" [51]. Worries about litigation ("covering myself") also had a tangible effect on decisions [52]. Resolving that type of tension through moral debate could be facilitated by the resources.

\section{Implications for practice}

The findings answer a call in the literature for a moral debating resource to support practice virtue ethics/phronesis-based approach for ethical decisionmaking in medical practice. This is despite the detractors of such an approach who argue that this is an unreachable ideal and phronesis is conceptualised in different forms [e.g. 14]. The form of conceptualisation used is the practice virtue ethics version as advocated by MacIntyre [11] and supported by others [e.g. 17-19] in medically 
contextualised studies. Furthermore, given the argument that the role of doctors is changing from being the sole guardians of medical knowledge [53, 54] to being facilitators of practically wise decisions, weight is given to this approach being conceptually and practically relevant right now.

We argue these fifteen virtues represent an intra-medical practice collective for the doctors interviewed and observed $(n=131)$. One practitioner possessing all these virtues in their character is an unrealistic ideal, or as Curzer states: "one person can have some but not all the virtues" [55]:70]. Therefore, rather than them being a set of individual character virtues in the original Aristotelian tradition, we argue that the table provides their collective ethos and so aligns with the neo-Aristotelian concept of practice virtue ethics.

In this collective form and when conveyed in the highly accessible video series and online App the 15 virtues provide a form of practical wisdom that can be used in both professional education and practice for moral debate related to ethical decision-making [56]. This supports the notion that such an approach leads towards professional fulfilment and practice excellence [11]. The flexibility of the continua allows phronesis to be cultivated within practice and across related practices in the wider community; which according to MacIntyre [11] is also part of schema to establish virtuous practices and a telos (purpose) of well-being for all in the community.

A virtuous act "hits the target" by deriving an understanding of the situation and acknowledging all its pertinent features [22]:11] and in so doing requires moral judgement to discern how to act wisely. Our findings mean practice virtue ethics and phronesis can be used to complement other ethical approaches and clinical knowledge, leading to treatment plans/decisions that consider the particularities in each case. This is integral to reaching a diagnosis and proposing a plan of care that gives primacy to the best interest of the patient, and the community. Our findings emphasize that even when virtues are recognised for that particular practice (e.g. negotiation, reflection, cultural competence, collaboration, recognising limits to treatment etc.), knowing where to act on the continuum requires discernment that is provided by the intellectual virtue of phronesis [11].

So that moral reasoning and relevance work simultaneously [57], this framework offers practitioners a helpful stimulus to achieve that. On this view, we agree with others about introducing practical wisdom during the "formative development of medical students' ethical reasoning" [58, 59]:241] which also enriches teaching methods for ethics [60].

Cribb argues that to deliver independent rigorous (moral) thinking, relevant to the situation at hand, without sacrificing rigour for relevance, is a challenge for translational ethics [57]. By consolidating the 15 virtue continua as 'Collective Practical Wisdom' and conveying them in an enacted seven-part video series we created a contemporary moral debating resource that responds well to the challenge of translational ethics identified by Cribb [57] and is applicable in varied contexts. As stated earlier, rather than a deontological prescription as the definitive, 'this is how it should be done', the series provides a stimulus for reflection before, during and after medical decision-making. The way this is achieved is to use the videos in undergraduate and/or post-graduate(UG/PG) medical educational or continuous professional development (CPD) programmes to support the cultivation and development of practical wisdom for groups of practitioners. For instance, in a CPD programme they could view the series and then debate in groups the virtues they observe and how it relates to the current cases and dilemmas they are experiencing. The flexibility and adaptability of the resources means that the practitioners can add a virtue continuum of relevance to the situation. Thus, practitioners can add and remove virtues, move along the continua and integrate with the particularities of the decision-making process for the individual case.

\section{Limitations}

Our study does not claim to have captured all the virtues required for good and wise clinical decision-making, or to be offering yet another deontological guide, to be followed by medical doctors. However, it does offer a contemporary moral debating resource for medical educators and practitioners in their peer groups to decide on the relevant virtues for their context and the case under consideration.

This study is focussed on one healthcare professiondoctors. Further research is therefore needed, with inter-professional/disciplinary teams and integrated care groups to understand what it means for them individually and as a collective to make ethically wise and good decisions for patients and their communities. This is especially relevant to patient groups where a wide group of different professions must come together to make the right decision at the right time and in the right place e.g. older people with frailty and people suffering from mental health issues. To this end the research team have already initiated new proposals that address this call and gap in current understanding of ethical healthcare decision-making. 


\section{Conclusions}

Phronesis and practice virtues are interdependent. Phronesis helps adapt the practice virtues that enable doctors to make the right decisions for this patient, and the wider community. We offer here a starting point of "collective practical wisdom" from a group of medics at all stages in their careers. In this regard, the moral debating resource described is a credible tool for introducing and cultivating the concept of phronesis. As well as complementing the knowledge possessed by qualified professionals, medical trainees do not have to wait until they are older to be purveyors of wisdom or wise decisions. Instead, the latter could start to learn some phronesis from the wider medical community at the start of their careers. The videos, and accompanying resources, can be used both as an in-action and post-action debriefing tool. Future practice, research and policy on medical decision-making should benefit from applying this non-prescriptive approach to addressing the health and well-being of patients and wider society. The tool and the virtue continua support the General Medical Council's (GMC) 'Generic Professional Capabilities Framework' [61] and, from a policy perspective, the GMC's 'Outcomes for Graduates', which lays down the professional and ethical responsibilities for its doctors [62]:9-10].

There is an understanding that "the aim of medical education is to develop doctors who are reflective, empathetic, trustworthy, committed to patient welfare and able to deal with complexity and uncertainty" [60]:431]. The 15 virtues in Table 2, interpreted from the narratives of our participants are the in-situ virtues that these UK practitioners conveyed as important to their practice. In medical ethics undergraduate, postgraduate and CPD programmes the resources described here can be used to examine and debate ethical dilemmas and challenges faced by actors in low, medium or high resource healthcare contexts and therefore are of international relevance.

\section{Supplementary Information}

The online version contains supplementary material available at https://doi. org/10.1186/s12910-021-00581-y.

Additional file 1: Title-Final 15 Virtues Dataset. Description- the manuscript shows only 4 findings while, as stated in the manuscript, this supplementary file shows all the consolidated 15 virtues gleaned from the participant's narratives along with participants' quotes.

Additional file 2: Title-Virtues from observation data. Description- the file shows the virtues observed during observation of MTD, in tabulated form.

\section{Abbreviations}

CPD: Continuous professional development; Exp.: Experienced; FY: Foundation year; GP: General practitioner; GMC: General Medical Council; MDT: Multidisciplinary team; NHS: National Health Service; Obs:: Observations; PMC: Phronesis and the Medical Community; PG: Postgraduate; REC: Research Ethics Committee; UG: Undergraduate; V.: Virtue.

\section{Acknowledgements}

This research was made possible through the AHRC grant (AH/M006646/1). We would like to thank our participants without whom this research would not have been possible. We are grateful to Dr. lestyn Williams for providing useful comments on the earlier drafts and to the two reviewers who provided useful comments to the submitted manuscript.

We acknowledge University of Cumbria for producing the video series that provide the moral debating resource/tool. We would also like to thank Dr. Richard Bosworth for developing the Wisdom Wheel App. (https://phronesis. medicloud.io/) based on the concept developed by AM of a staged approach of virtues to decision-making.

\section{Authors' contributions}

MC: Project management of the research, methodology design and writing, writing the outline and abstract, additions to the background, methodology, discussion and conclusions plus a full and final edit. AM: Research fellow: data collection, data analysis, presenting the findings and introducing the concept of a staged process of phronetic decision-making and writing the initial draft. Contributing to: Background, methodology, major contribution to findings (and the virtue contua table, tabulating the virtue ethics framework and the virtue/cohort table), major part of the discussion and conclusion, and subsequent, multiple, revisions and the final version of the paper. $\mathrm{CH}$ : CoInvestigator, assisting PI with project management. Research data collection, coding and analysis of findings. Additions to the background, methodology, discussion and conclusions. CW: Research fellow: data collection, data analysis including patient and community perspectives on trust and phronesis, contributing to the findings. Communication of findings via social media, conference posters and conversion of virtues into series of practitioner questions. Development of evaluation framework AB: Co-Investigator for the project. Member of the operations and steering groups, involved in data collection, coding and data analysis, contributed to refining of the virtues, development of the virtue continuum table, full review and critical edit of the draft manuscript at different stages of development and review of the final version of the paper. CT: Co-Investigator. Data collection, analysis of findings. Additions to the background, methodology, discussion and conclusions. All authors have read and approved the manuscript.

\section{Funding}

Arts and Humanities Research Council (AHRC) research award funding: $\mathrm{AH} /$ M006646/1. AHRC contributed to the design of this study by providing peer review comments on the detailed research design methods- all of which were incorporated.

\section{Availability of data and materials}

The datasets generated and/analysed during the current study are publicly available at: https://www.birmingham.ac.uk/Documents/college-social-scien ces/social-policy/phronesis/phronesis-in-medical-decision-making.pdf. The final dataset of the 15 virtues presented as the findings from this research are also available as supplementary files (1 and 2).

\section{Ethics approval and consent to participate}

The ethics approval for this project was sought at the outset, before data collection commenced, from the University of Birmingham (Application No. ERN_15-0172) and it was approved by the Science, Technology, Engineering and Mathematics Ethical Review Committee on 28th September 2015. Ethics approval was also sought from the University of Nottingham, Faculty of Medicine and Health Sciences REC (Ref. No: L13102015 SoM Birm ERN_150172), the University of Warwick, Biomedical and Scientific REC (BRSC Ref: REGO 2015-1720) and Ministry of Defence REC (MODREC). Approval was given on 25th October 2015 and 4th November 2015 from the Universities of Nottingham and Warwick, respectively. Approval was given by MODREC on 4th May 2016 (Reference Number: 724/MODREC/16). Ethics approval was also obtained before commencing observations in the second phase of data collection from the Health Research Authority (IRAS Project I.D. 227550). Approval was given on 8th August 2017 (REC Reference: 18/HRA/0203). Written consent to participate in this study was obtained from all participants before commencing interviews and observations.

Consent for publication

Not applicable. 


\section{Competing interests}

The authors declare they have no competing interests.

\section{Author details}

${ }^{1}$ Health Services Management Centre, University of Birmingham, Birmingham, UK. ${ }^{2}$ Warwick Medical School, University of Warwick, Coventry, UK. ${ }^{3}$ Emergency Medicine, University Hospitals Coventry and Warwickshire, Coventry, UK. ${ }^{4}$ Department for Continuing Education, University of Oxford, Oxford, UK.

Received: 14 December 2019 Accepted: 31 January 2021

Published online: 18 February 2021

\section{References}

1. Dalglish SL, Rodríguez DC, Harouna A, Surkan PJ. Knowledge and power in policy-making for child survival in Niger. Soc Sci Med. 2017;177:150-7. https://doi.org/10.1016/j.socscimed.2017.01.056.

2. Gallagher S, Little M, Hooker C. The values and ethical commitments of doctors engaging in macroallocation: a qualitative and evaluative analysis. BMC Med Ethics. 2018;19(1):75. https://doi.org/10.1186/s1291 0-018-0314-1.

3. Upshur R. Do guidelines make sense? No AnnalsFamily Medicine. 2014;12(3):202-3. https://doi.org/10.1370/afm.1654.

4. Kotzee B, Paton A, Conroy M. Towards an empirically informed account of $<i>$ Phronesis</i> in medicine. Perspect Biol Med. 2016;59(3):337-50. https://doi.org/10.1353/pbm.2016.0029.

5. Page K. The four principles: Can they be measured and do they predict ethical decision making? BMC Med Ethics. 2012;13(1):10. https://doi. org/10.1186/1472-6939-13-10.

6. Christen M, Ineichen C, Tanner C. How, "moral" are the principles of biomedical ethics? A cross-domain evaluation of the common morality hypothesis. BMC Med Ethics. 2014;15(1):47. https://doi. org/10.1186/1472-6939-15-47.

7. Torjuul K, Nordam A, Sørlie V. Action ethical dilemmas in surgery: an interview study of practicing surgeons. BMC Med Ethics. 2005;6(1):7. https:// doi.org/10.1186/1472-6939-6-7.

8. Conroy M, Hale C, Malik A, Weir C, Biggerstaff D, Brockie A et al. Phronesis in Medical Decision Making: Medical Leadership, Virtue Ethics and Practical Wisdom. AHRC Final Report for Phronesis and the Medical Community. 2018. https://www.birmingham.ac.uk/Documents/college-socia l-sciences/social-policy/phronesis/phronesis-in-medical-decision-makin g.pdf. 2019

9. Jonsen A, Siegler A, Winslade W, editors. Clinical Ethics: a practical approach to ethical decisions in clinical medicine. 8e ed. New York: McGraw Hill Medical; 2010.

10. Toulmin S. How medicine saved the life of ethics. Perspect Biol Med. 1982;25(4):736-50.

11. Maclntyre A. After virtue. A study in moral theory. London: Gerald Duckworth \& Co.Ltd; 1981

12. Beresford EB. Can phronesis save the life of medical ethics? Theoret Med. 1996;17(3):209-24. https://doi.org/10.1007/BF00489446.

13. Aristotle. The Nicomachean ethics wordsworth classsics of the world literature. Hertfordshire: Wordsworth Editions Ltd; 1996.

14. Kristjansson K. Phronesis as an ideal in professional medical ethics: some preliminary positionings and problematics. Theor Med Bioeth. 2015;36(5):299-320. https://doi.org/10.1007/s11017-015-9338-4.

15. Jonsen AR, Toulmin SE. The abuse of casuistry: a history of moral reasoning. 1st ed. Berkley: University of California Press; 1988.

16. Pellegrino ED, Thomasma DC. The virtues in medical practice. Oxford: OUP; 1993.

17. Kaldjian LC. Practicing medicine and ethics: integrating wisdom, conscience, and goals of care. New York: Cambridge University Press; 2014.

18. Montgomery K. How doctors think: clinical judgment and the practice of medicine. New York: Oxford University Press; 2006.

19. Toon P. A flourishing practice? London: Royal College of General Practitioners; 2014

20. Oakley J, Cocking D. Virtue ethics and professional roles. New York: Cambridge University Press; 2001.

21. Pellegrino ED. Professionalism, profession and the virtues of the good physician. Mt Sinai J Med. 2002;69(6):378-84.
22. Bailey $\mathrm{O}$. What knowledge is necessary for virtue? J Ethics Soc Philos. 2010;42(2):1-18.

23. Kaldjian LC, Weir RF, Duffy TP. A clinician's approach to clinical ethical reasoning. J Gen Intern Med. 2005;20(3):306-11. https://doi.org/10.111 1/j.1525-1497.2005.40204.x.

24. Torjuul K, Nordam A, Sørlie V. Ethical challenges in surgery as narrated by practicing surgeons. BMC Med Ethics. 2005;6(1):2. https://doi. org/10.1186/1472-6939-6-2.

25. Carr D, Arthur J, Kristiánsson K, editors. Varieties of Virtue ethics. New York: Palgrave Macmillan; 2017.

26. Christen M, Ineichen C, Tanner C. How, "moral" are the principles of biomedical ethics? A cross-domain evaluation of the common morality hypothesis. BMC Med Ethics. 2014;15:47. https://doi. org/10.1186/1472-6939-15-47.

27. Kon AA. The role of empirical research in bioethics. Am J Bioeth. 2009. https://doi.org/10.1080/15265160902874320.

28. Ford S, Schofield T, Hope T. Observing decision-making in the general practice consultation: Who makes which decisions? Health Expect Int J Public Particip Health Care Health Policy. 2006;9(2):130-7. https://doi.org/ 10.1111/j.1369-7625.2006.00382.x.

29. Jordens C, Little M. In this scenario, I do this, for these reasons': narrative, genre and ethical reasoning in the clinic. Soc Sci Med. 2004;58(9):1635-45

30. Little M, Gordon J, Markham P, Rychetnik L, Kerridge I. Virtuous acts as practical medical ethics: an empirical study. J Evaluat Clin Pract. 2011;17(5):948-53. https://doi.org/10.1111/j.1365-2753.2011.01730.x.

31. Jones EK, Kittendorf AL, Kumagai AK. Creative art and medical student development: a qualitative study. Med Educ. 2017;51(2):174-83. https:// doi.org/10.1111/medu.13140.

32. Conroy M, Clarke H, Wilson L. Connected Health and Social Care Communities. AHRC. 2012. http://www.ahrc.ac.uk/documents/project-repor ts-and-reviews/connected-communities/connected-health-and-socia l-care-communities/. Accessed 17 Oct 2016.

33. Bruce C. Not Principlism nor Casuistry, Not Narrative Ethics nor Clinical Pragmatism: A Case for Proceduralism. In: Finder SG BM, editor. Peer Review, Peer Education, and Modeling in the Practice of Clinical Ethics Consultation: The Zadeh Project [internet]. Cham (CH): Springer 2018.

34. Barber S, Moreno-Leguizamon CJ. Can narrative medicine education contribute to the delivery of compassionate care? A review of the literature. Med Human. 2017;43(3):199-203. https://doi.org/10.1136/medhu m-2017-011242.

35. Zaharias G. What is narrative-based medicine? Narrative-based medicine 1. Can Fam Phys. 2018;64(3):176-80.

36. Flyvbjerg B, Landman T, Schram S, editors. Real social science: applied phronesis. Cambridge: Cambridge University Press; 2012.

37. Schugurensky D. Challenge for Change launched, a participatory media approach to citizenship education. In: History of Education. The Ontario Institute for Studies in Education of the University of Toronto (OISE/UT). 2005. 2019

38. Malik AY, Conroy M, Weir C, Turner C, Hale C. Impact Assessment of Phronesis Resources on Ethical Decision Making for Doctors: University of Birmingham, Centre HSM;2020. Report No.: 1.

39. Conroy M. An Ethical Approach to Leading Change: An Alternative and Sustainable Application. Basingstoke Palgrave Macmillan; 2010.

40. Kaldjian LC. Teaching practical wisdom in medicine through clinical judgement, goals of care, and ethical reasoning. J Med Ethics. 2010;36(9):558-62. https://doi.org/10.1136/jme.2009.035295.

41. Malik A, Conroy M, Turner C. Phronesis in medical ethics: courage and motivation to keep on the track of rightness in decision-making. Health Care Anal. 2020;28(2):158-75. https://doi.org/10.1007/s10728-020-00398 $-7$.

42. Carr D. Cultivating moral character and virtue in professional practice. Oxford: Abingdon; 2018.

43. MacIntyre A. God, philosophy, universities: a selective history of the catholic philosophical tradition. Lanham, MD: Rowman \& Littlefield; 2009.

44. Oakley J. Virtue Theory. In: Ashcroft R, Dawson. A., Draper, H. \& McMillan, J., editor. Principles of Healthcare Ethics. John Wiley and Sons Ltd.; 2007. p. $87-91$.

45. Walker RL, Ivanhoe PJ. Working virtue: virtue ethics and contemporary moral problems, vol. 4. Oxford: Oxford University Press; 2007. 
46. Kristiansen $M$. The difference that kind and compassionate care makes. theBMJopinion: BMJ; 2018.

47. Pellegrino ED, Thomasma DC. For the Patient's Good: a Restoration of Beneficence in Health care New York: Oxford University press; 1988.

48. Padela Al, Malik AY, Curlin F, De Vries R. [Re]considering Respect for Persons in a Globalizing World. Developing World Bioethics. 2015;15(2):98106. https://doi.org/10.1111/dewb.12045.

49. Farrington N, Mandy F, Richardson A, Sartain S. Exploring the role of practical nursing wisdom in the care of patients with urinary problems at the end of life: a qualitative interview study. J Clin Nurs. 2015;24:2745-56.

50. Brummell S, Seymour J, Higinbottom G. Cardiopulmoary resuscitation decisions in the emergency department: An ethnography of tacit knowledge in practice. Soc Sci Med. 2016;156:47-54.

51. Vincent C, Taylor-Adams S, Stanhope N. Framework for analysing risk and safety in clinical medicine. BMJ (Clinical research ed). 1998;316(7138):1154-7.

52. Hood L, Fenwick J, Butt J. A story of scrutiny and fear: Australian midwives' experiences of an external review of obstetric services, being involved with litigation and the impact on clinical practice. Midwifery. 2010;26(3):268-85.

53. Haug MR. The Erosion of professional authority: a cross-cultural inquiry in the case of the physician. The Milbank Memorial Fund Quarterly. 1976;54(1):83-106.

54. Clarke JN. A multiple paradigm approach to the sociology of medicine, health and illness. Sociol Health IIIn. 1981;3(1):89-104.

55. Curzer HJ. Against Idealization in Virtue Ethics. In: Carr DA, James. Kristjánsson, Kristján., editor. Varieties of Virtue Ethics. UK: Palgrave Macmillan; 2017. p. 53-71.
56. Shelton W. Can virtue be taught? Acad Med J Assoc Am Med Coll. 1999;74(6):671-4.

57. Cribb A. Translational ethics? The theory-practice gap in medical ethics. J Med Ethics. 2010;36(4):207-10. https://doi.org/10.1136/jme.2009.029785.

58. Kobert LJ. Teaching Wisdom : project at University of Virginia. University of Virginia. 2016 https://news.virginia.edu/content/teaching-wisdom-phron esis-project-brings-practical-wisdom-medical-school. Accessed 4 Apr 2019.

59. Dowie A. Phronesis or "practical wisdom" in medical education. Med Teach. 2000;22(3):240-1. https://doi.org/10.1080/01421590050006188.

60. Campbell AV, Chin J, Voo TC. How can we know that ethics education produces ethical doctors? Med Teach. 2007;29(5):431-6. https://doi. org/10.1080/01421590701504077.

61. GeneralMedicalCouncil(GMC). Generic professional capabilities framework 2017. https://www.gmc-uk.org/-/media/documents/Generic_profe ssional_capabilities_framework_0817.pdf_70417127.pdf. Accessed 18 Jan 2019.

62. GeneralMedicalCouncil(GMC). Outcomes for Graduates. 2018. https:// www.gmc-uk.org/-/media/documents/dc11326-outcomes-for-gradu ates-2018_pdf-75040796.pdf. Accessed 18 Jan 2019.

\section{Publisher's Note}

Springer Nature remains neutral with regard to jurisdictional claims in published maps and institutional affiliations.
Ready to submit your research? Choose BMC and benefit from:

- fast, convenient online submission

- thorough peer review by experienced researchers in your field

- rapid publication on acceptance

- support for research data, including large and complex data types

- gold Open Access which fosters wider collaboration and increased citations

- maximum visibility for your research: over 100M website views per year

At BMC, research is always in progress.

Learn more biomedcentral.com/submissions 